\title{
Calculation model of the anisotropy of strength at compression of masonry
}

\author{
Valery Derkach ${ }^{1 *}$, Anton Galalyuk ${ }^{1}$ \\ ${ }^{1}$ RUE "Institute BeINIIS" - Scientific technical center, Belarus
}

\begin{abstract}
The article presents the results of experimental studies of anisotropy compressive strength of solid ceramic brick masonry. It was found that the minimum values of the compressive strength of masonry made of ceramic bricks on a standard lime-cement mortar take place with the direction of the compressive force at angles to the horizontal seams of the masonry $45^{\circ}-67^{\circ}$. It is shown that under the action of a compressive force at angles $0^{\circ}<\theta<90^{\circ}$ on the mechanism the destruction of masonry is affected by the shear stresses arising in it, the values of which increase with decreasing angle of direction of the compressive force to horizontal seams of masonry. A design model of strength is proposed masonry when compressed at different angles to horizontal mortars masonry seams.
\end{abstract}

\section{Introduction}

Among the many problems of modern urban development, the problem of preserving historical heritage occupies one of the leading places. Work on research and assessment of technical condition of preserved stone buildings and structures representing cultural historical value is of outmost importance. In such buildings, as a rule, there are vaulted structures made of ceramic bricks of various kinds, as well as overhead lintels of an arched or lancet outlines. Surveys of old buildings show that many of these structures do not fit into those given in the methodological and normative documents, theoretical design schemes, due to degradation of masonry, loss of part of the vertical supports, spring arches, ties or other elements. Under the action of operational load or uneven settlement of foundations geometric shapes of vaults and arches predetermine the direction force flows arising in them at different angles to the mortar joint of masonry. As practice shows, the angle of inclination of the compressive efforts to mortar joints of masonry in the specified structures, depends on their shape, the ratio of the span to the lifting arrow and is in within $10^{\circ}-40^{\circ}$. Calculated assessment of the reliability of existing spacers stone structures is usually performed by checking the limit states by the method of partial coefficients. In this case, the effects of influences (values of principal stresses and their trajectories) are set based on calculations of structures by the finite element method using modern computing systems. Masonry in calculation models is considered as a solid, homogeneous, orthotropic material, directions of the principal axes of anisotropy in which coincide with horizontal and vertical mortar joints. Received on calculations values of the principal stresses are

\footnotetext{
* Corresponding author: v-derkatch@yandex.by
} 
compared with values of the strength of the masonry in the corresponding direction in relation to the principal axes of anisotropy [1]. While in European and Russian standards for the design of stone structures EN 1996-1-1 and SP 52.02.01-2020 analytical dependences for the calculation compressive strength of masonry are provided only under compressive force perpendicular and parallel to the reference plane of the masonry products, which makes it impossible to adequately perform limit checks states of spacer stone structures.

\section{Results of experimental studies of anisotropy compressive strength of masonry}

In order to obtain data on anisotropy of the compressive strength of masonry at the RUE branch "BelNIIS" - STC tested samples made from solid ceramic bricks exposed to compressive loads at different angles to horizontal (reference) mortar joints. In total, five experimental batches were tested, including five masonry specimens for each angle of inclination of the compressive force. Masonry specimens were made from solid ceramic brick M150 on lime-cement mortar with strength $f_{m}=7.9 \mathrm{MPa}$.
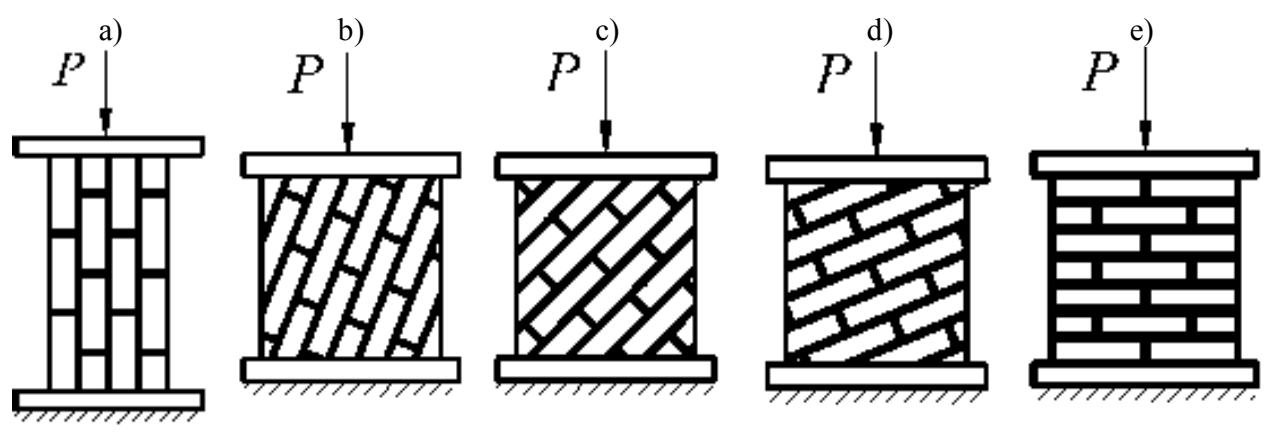

$$
\mathrm{a}-\theta=90^{\circ} ; \mathrm{b}-\theta=67,5^{\circ} ; \mathrm{c}-\theta=45^{\circ} ; \mathrm{d}-\theta=22,5^{\circ} ; \mathrm{e}-\theta=0^{\circ}
$$

Fig. 1. Compressive load testing scheme for masonry specimens at angles $\theta$ to horizontal mortar joints.

It was found that the compressive strength of masonry and its nature fracture is largely determined by the angle of application compressive load to horizontal mortar joints. Minimal values of the compressive strength of the masonry took place at angles $\theta=45^{\circ}$ $67.5^{\circ}$. At an angle of inclination $\theta=67.5^{\circ}$ destruction of prototypes of masonry occurred due to a shift in the plane of horizontal mortar joints, and at $\theta=45^{\circ}$, in addition to a shift in the plane of mortar joints, there was rupture of masonry by brick. The specified character of destruction is explained by the fact that under the action of a compressive force at angles 0 $0^{\circ}<\theta<90^{\circ}$ in the picture the destruction of the masonry is reflected in the tangents arising in it stresses whose values increase with decreasing direction angle $P$ to horizontal masonry joints. The nature of the destruction of experienced samples is shown in Figure 2. 
a)

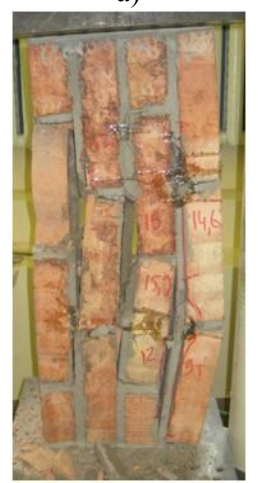

d)

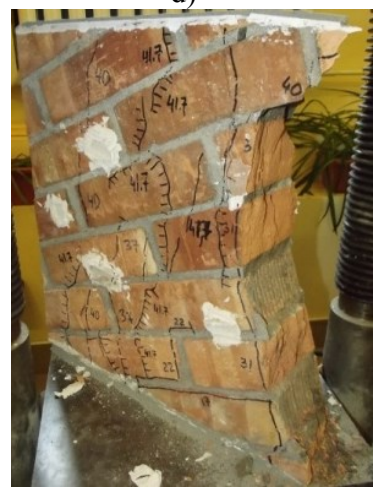

b)

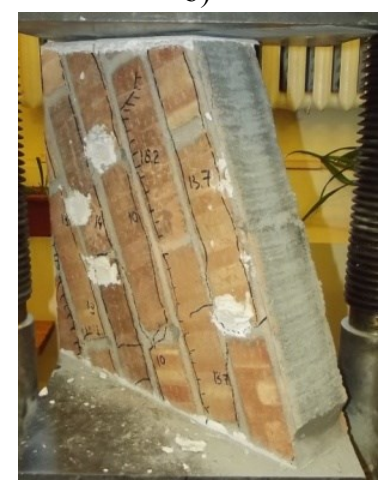

e)

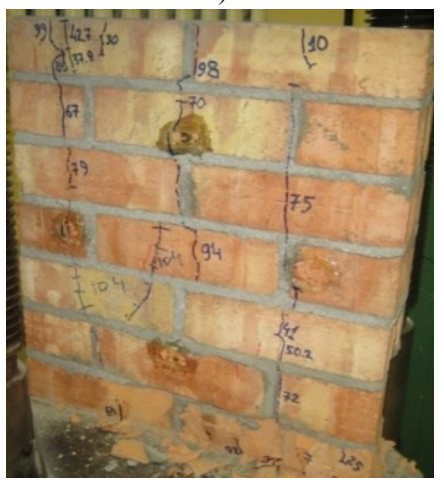

c)

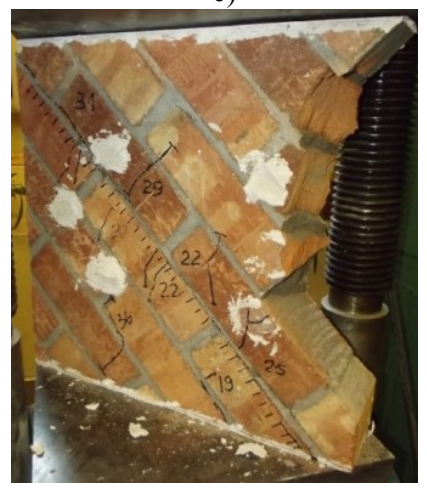

$\mathrm{a}-\theta=90^{\circ} ; \mathrm{b}-\theta=67,5^{\circ}$;

$\mathrm{c}-\theta=45^{\circ} ; \mathrm{d}-\theta=22,5^{\circ}$

$\mathrm{e}-\theta=0^{\circ}$

Fig. 2. Character destruction of experienced masonry samples.

\section{Calculation model of the strength of masonry in compression at an angle to horizontal mortar joints}

Experimental studies show that at angles $\theta$ from $45^{\circ}$ to $67.5^{\circ}$ (Figure 1) the reason for the destruction of the masonry is its shift in the plane support mortar joints. If the angle $\theta$ is in the range $67.5^{\circ}-90^{\circ}$, then the nature of the destruction of the masonry is determined by the compressive strength of the brick in direction of the butt surface, and at $\theta$ in the range $22.5^{\circ}$ $-0^{\circ}$ by the compressive strength of the brick in the direction of the supporting surface.

If the angle of inclination of the compressive force to the horizontal mortar differs from $0^{\circ}$ and $90^{\circ}$, then tangents $\tau$ and normal compressive stresses $\sigma$ occur, the ratio of which changes depending on the angle $\theta$ (Figure 3).
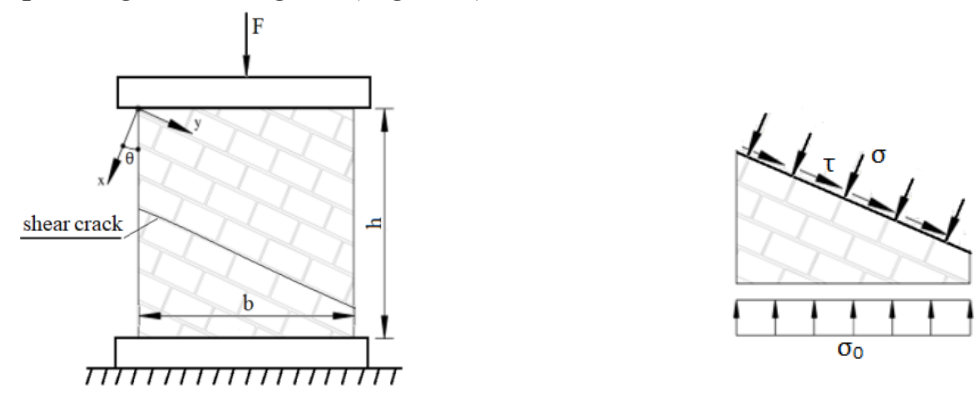

Fig. 3. Scheme of distribution of tangents and normal stresses in the support mortar joints of the masonry. 
In accordance with Figure 3, the values of tangents and normal compressive stresses acting in the plane of the support seams can be determined by formulas (1), (2).

$$
\begin{gathered}
\sigma=\sigma_{0} \cdot \cos ^{2} \theta \\
\tau=\sigma_{0} \cdot \cos \theta \cdot \sin \theta
\end{gathered}
$$

where $\sigma_{0}$ - compressive stresses in masonry, the value of which is set by the formula (3):

$$
\sigma_{0}=\frac{F}{A}
$$

where $F$ - value of the compressive force;

$A=b \cdot t$ - cross-sectional area of masonry ( $b, t-$ the width and thickness of the masonry, respectively).

The destruction of masonry under the action of a compressive force $F$ under angles $\theta$ in the range $30^{\circ}-70^{\circ}$ occurs when the shear stresses in mortar joints achieve the shear strength of the masonry $\left(f_{v}\right)$. Taking $\tau$ equal to the value of $f_{v}$, and $\sigma_{0}$ equal to the value of the compressive strength of the stone masonry $\left(f_{\theta}\right)$ we get:

$$
f_{v}=f_{\theta} \cdot \cos \theta \cdot \sin \theta
$$

The value of the shear strength of the masonry in the plane of the reference mortar joints are determined by the Coulomb-Mohr formula (4):

$$
f_{v}=f_{v 0}+\sigma \cdot \operatorname{tg} \varphi
$$

where $f_{v 0}$ - initial value of the shear strength of the masonry (shear bond strength);

$\operatorname{tg}_{\varphi}-$ coefficient of internal friction.

According to [1], the $f_{v}$ value obtained by formula 4 should not exceed the values of the tensile strength of the masonry product, which is taken equal to $0.065 f_{b}$, where $f_{b}$ is the normalized compressive strength of the masonry product. (5):

Taking into account (1) and (3), formula (4) can be represented in the form of equation

$$
f_{\theta} \cdot \cos \theta \cdot \sin \theta=f_{v 0}+f_{\theta} \cdot \cos ^{2} \theta \cdot \operatorname{tg} \varphi
$$

From equation (5), the compressive strength of masonry at angles to horizontal mortar joints:

$$
f_{\theta}=\frac{f_{v 0}}{\cos \theta \cdot \sin \theta-\cos ^{2} \theta \cdot \operatorname{tg} \varphi}
$$

The $f_{\theta}$ value obtained by formula (6) should not exceed the value:

$$
f_{\theta}=\frac{0,065 f_{b}}{\cos \theta \cdot \sin \theta}
$$

Compressive strength of masonry at angles $0^{\circ}<\theta<30^{\circ}$ and $70^{\circ}<\theta<90^{\circ}$ determined by linear interpolation.

For a clear comparison of the results of experimental theoretical studies, a graph was built (Figure 4), on which the strength values is calculated by the proposed model are given 
for compression of masonry at an angle of $67.5^{\circ}$ to horizontal mortar joints $f_{\text {calc. }}$ with respect to the corresponding experimental data $f_{\text {exp }}$.

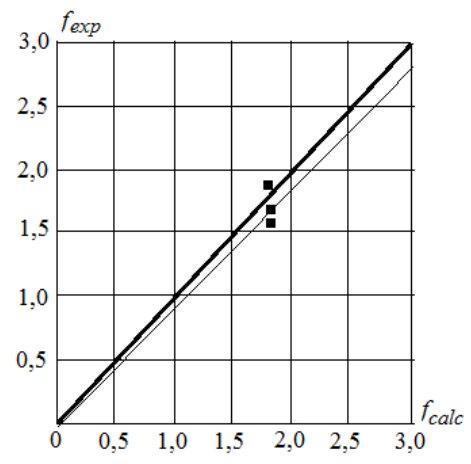

Fig. 4. Comparison of calculated and experimental values compressive strength $\theta=67.5^{0}$.

\section{Conclusion}

Based on the above, you can do the following conclusion:

1. The strength of masonry in compression and the nature of its destruction depend on the angle of application of the compressive load to the horizontal mortar seams. Based on the results of experimental studies it was found that the minimum values of the compressive strength of the masonry made of ceramic bricks on standard lime-cement solution took place when the compressive force was directed at angles to the horizontal seams of the masonry $\theta=45^{\circ}-67.5^{\circ}$.

2. A computational model of the compressive strength of masonry is proposed at an angle to horizontal mortar joints, taking into account the compressive strength of the brick, as well as the adhesion strength of the mortar with masonry products and the angle of internal friction. Data characteristics can be established by examining stone designs [5].

\section{References}

1. Galalyuk, A.V. Consideration of the anisotropy of the strength of the masonry at assessment of the bearing capacity of historical spacers /A.V. Galalyuk, V.N.Derkach // Actual problems of research materials, structures, technologies and organization of construction in transboundary aspect: a collection of articles of the II International Scientific conferences. - Brest: BrSTU Publishing House. - 2017. P. 26-31.

2. Derkach, V.N. Anisotropy of Compressive Strength of Masonry / V.N. Derkach // Scientific and technical statements of SPbSPU - Science and education. - 2011. - No. 3 (130). - P. 181-186.

3. Derkach, V.N. Study of the strength of masonry in action compressive force parallel to horizontal mortar joints /V.N. Derkach // Bulletin of BrSTU: Building and architecture. - 2011. - No. 1 (67) - P. 43-47.

4. Galalyuk, A.V. Compressive strength of masonry under various corners to horizontal mortar joints / A.V. Galalyuk //Construction Science - 2014: theory, education, practice, innovation (dedicated to the 55th anniversary of ISiA NArFU). Collection of works of international scientific and technical Conf., Arkhangelsk, May 22-23, 2014 Ed. Labudin B.V. - Arkhangelsk: Publishing house of LLC "Printing house" TOCHKA ", 2014. - P. 68-73. 
5. Orlovich, R.B. Evaluation of the strength of masonry mortars at survey of stone buildings / R.B. Orlovich, V.N.Derkach //Engineering and construction journal. - 2011. - No. 7 (25). - P. 3-10. 